\title{
BMJ Open Prevalence and predictors of oral to intravenous antibiotic switch among adult emergency department patients with acute bacterial skin and skin structure infections: a pilot, prospective cohort study
}

\author{
Michael Quirke (1) , ${ }^{1,2}$ Niamh Mitchell, ${ }^{3}$ Jarlath Varley, ${ }^{3}$ Stephen Kelly, ${ }^{2}$ \\ Fiona Boland (D) , ${ }^{4}$ Adrian Moughty, ${ }^{5}$ Joseph McKeever, ${ }^{3}$ Tom Fahey (D) , \\ Abel Wakai (10) ${ }^{1,2}$
}

To cite: Quirke M, Mitchell N, Varley J, et al. Prevalence and predictors of oral to intravenous antibiotic switch among adult emergency department patients with acute bacterial skin and skin structure infections: a pilot, prospective cohort study. BMJ Open 2020;10:e034057. doi:10.1136/ bmjopen-2019-034057

\section{- Prepublication history for} this paper is available online. To view these files, please visit the journal online (http://dx.doi. org/10.1136/bmjopen-2019034057).

Received 06 September 2019 Revised 11 June 2020 Accepted 16 June 2020

D Check for updates

(c) Author(s) (or their employer(s)) 2020. Re-use permitted under CC BY-NC. No commercial re-use. See rights and permissions. Published by BMJ.

For numbered affiliations see end of article.

Correspondence to

Dr Abel Wakai; awakai@rcsi.ie

\section{ABSTRACT}

Objective To determine the prevalence and predictors of oral to intravenous antibiotic switch among adult emergency department (ED) patients with acute bacterial skin and skin structure infections (ABSSSIs).

Design Multicentre, pilot cohort study.

Setting Three urban EDs in Dublin, Ireland.

Participants Consecutive ED patients aged $>16$ years old with ABSSSIs between March 2015 and September 2016.

Intervention Oral flucloxacillin $500 \mathrm{mg}-1 \mathrm{~g}$ four times a day (alternative in penicillin allergy).

Primary and secondary outcome measures The primary outcome was to determine the prevalence and predictors of oral to intravenous antibiotic switch. Secondary outcomes were to determine the prevalence and predictors of receiving an extended course of oral antibiotic treatment and measurement of interobserver reliability for clinical predictors at enrolment.

Results Overall, 159 patients were enrolled of which eight were lost to follow-up and five were excluded. The majority of patients were male $(65.1 \%)$ and $<50$ years of age (58.2\%). Oral to intravenous antibiotic switch occurred in 13 patients $(8.9 \%$; $95 \% \mathrm{Cl} 4.8 \%$ to $14.7 \%)$. Increased lesion size (OR 1.74; $95 \% \mathrm{Cl} 1.09$ to 2.79 ), white cell count (OR 1.32; 95\% Cl 1.05 to 1.67), athlete's foot (OR $8.00 ; 95 \% \mathrm{Cl} 2.31$ to 27.71 ) and fungal nail infections (OR $7.25 ; 95 \% \mathrm{Cl} 1.99$ to 26.35 ) were associated with oral to intravenous antibiotic switch. $24.8 \%(95 \% \mathrm{Cl} 18.1 \%$ to $33.0 \%)$ of patients received an extended course of oral antibiotic treatment.

Conclusion The prevalence of oral to intravenous antibiotic switch in this pilot study is $8.9 \%(95 \% \mathrm{Cl} 4.8 \%$ to $14.7 \%$ ). We identify the predictors of oral to intravenous switch worthy of future investigation.

Trial registration number NCT02230813.

\section{BACKGROUND}

Acute bacterial cellulitis is a spreading, suppurative infection of the dermal and subdermal
Strengths and limitations of this study

- This is the first prospective study to measure the prevalence of oral to intravenous antibiotic switch among patients with acute bacterial skin and skin structure infections in a European emergency department setting, where community associated methicillin-resistant Staphylococcus aureus is not endemic.

- $55 \%$ of the cohort underwent a second independent assessment by a clinician during which over 30 different predictor variables for oral to intravenous antibiotic switch was recorded.

- Due to the relatively small number of patients enrolled who required oral to intravenous antibiotic switch, multivariable logistic regression was not performed, and the identified predictors require further study before their incorporation into clinical guidelines or decision aids.

- Telephone follow-up could have introduced recall bias.

- We are unable to account for the quantity of potentially eligible patients who were not enrolled to this study and this raises the possibility of selection bias.

tissues that induces a host response. ${ }^{1}$ It is a significant burden accounting for up to $3 \%$ of emergency department (ED) attendances and is second only to pneumonia as the most common indication for inpatient antibiotic treatment in Europe. ${ }^{23}$ The nomenclature used to describe the spectrum of skin, skin structure and soft tissue infections is confusing. Phenomenological descriptions of different types of infection (cellulitis, erysipelas and abscess), predisposing conditions (diabetic foot ulcer), eponymous diseases (Fournier's gangrene) and microbiological 
causes of infection (clostridial myonecrosis) have resulted in heterogeneous terminology, much of which has only historical relevance. ${ }^{45}$ Furthermore, there are inconsistencies between classifications of skin and skin structure infections issued by the US Food and Drug Administration (FDA) and the Infectious Diseases Society of America (IDSA), which have contributed to confusion in terminology. ${ }^{67}$ For the purposes of clinical trial design, the US FDA groups cellulitis/erysipelas, wound infections and abscesses together as acute bacterial skin and skin structure infections (ABSSSIs). The clinical practice guideline (CPG) issued by the IDSA, advises clinicians to consider the management of skin and soft tissue infections (SSTIs) as either 'purulent' (associated with purulent drainage, discharge or exudate) or 'non-purulent' (not associated with purulent drainage, discharge or exudate).

The recent epidemic of community-associated methicillin-resistant Staphylococcus aureus (CA-MRSA) has resulted in significantly increased ED attendances and hospital admissions secondary to purulent skin infections in the USA and Canada, where it is the most common identifiable cause of skin infection. ${ }^{8}{ }^{9}$ In contrast, it has recently been shown that CA-MRSA is rarely cultured in European ED settings, highlighting significant differences in the microbiological epidemiology of ABSSSIs internationally. ${ }^{10}$

There is a lack of research-based data to guide the risk stratification and management of ABSSSIs, particularly in ED settings. Existing CPGs have generally been derived by expert opinion and consensus ${ }^{111-13}$ and adherence to published guideline recommendations has also been shown to be poor. ${ }^{11-13}$ When initiating treatment for an episode of ABSSSI, clinicians attempt to minimise the risk of treatment failure while containing the costs of care and the risk of fostering antibiotic resistance. ${ }^{7}$ Knowledge of which clinical risk factors are associated with an escalation or switch in treatment from oral to intravenous antibiotic treatment would provide an evidence-based approach for ED clinicians to risk-stratify patients with ABSSSI during their initial ED attendance and prescribe the most appropriate route and dose of antibiotic treatment during the initial ED visit.

Previous studies have shown that up to $29.5 \%$ of ED patients require a change in the route or dose of their initially prescribed antibiotic regimen, variably described as 'treatment failure'. ${ }^{14-16}$ However, these studies were performed in Canada where there is a higher endemic rate of CA-MRSA, reducing their generalisabilty to European ED settings. Furthermore, in all three studies, eligible patients were treated with various doses of oral, intravenous or a combination of oral and intravenous antibiotics in the ED prior to discharge. A prospective study enrolling patients with similar baseline infection severity and in whom the treating clinician deems suitable for a 7-day course of oral antibiotics is important in order to reduce confounding in the measurement of predictors of escalation of antibiotic treatment.
The aim of this study was to determine the prevalence and predictors of oral to intravenous antibiotic switch among ED patients with ABSSSIs recruited from an area with a low prevalence of CA-MRSA. ${ }^{17}$

\section{METHODS}

A prospective cohort study of patients attending three urban EDs in Ireland was performed. The study was registered with ClinicalTrials.gov. The study population, inclusion and exclusion criteria, and statistical methods are detailed fully in the freely available study protocol. ${ }^{17}$

Since the descriptor ABSSSI is not yet in common use in Ireland and to allow comparison with research published in North America, we carefully instructed study recruiters to consider patients with cellulitis arising de novo and arising from a secondary cause such a wound infection, ulcer or abscess as eligible for enrolment. Abscesses or wound infections without coexisting evidence of cellulitis were not enrolled. Standard treatment for abscesses and wounds was permitted. Treatment for athlete's foot and lymphoedema when detected as a predictor variable was not specified and left to the discretion of the treating clinician. Patients aged $>16$ years were recruited on a $24 / 7$ basis by ED clinicians with a minimum of 2 years' experience in emergency medicine. Only patients deemed suitable for oral antibiotic therapy (flucloxacillin $500 \mathrm{mg}-1 \mathrm{~g}$ four times daily for 7 days), or a recommended alternative for penicillin-allergic patients, and discharged from the ED, were enrolled.

Patient care was not altered for this study, and informed consent was obtained from each participant. A standardised, closed-response, paper case report form assessing over 30 different predictor variables was completed at the bedside and a patient questionnaire completed. ${ }^{17}$ In order to reduce ascertainment bias and strengthen internal validity, a second study recruiter, independent of the first recruiting clinician's assessment and choice of antibiotic treatment route and dose, repeated a second assessment for patient predictor variables and final agreement with patient diagnosis and disposition.

Follow-up was performed at day 14 by telephone when patients were asked whether their symptoms had improved after their prescribed 7-day course of oral flucloxacillin (or alternative for penicillin allergic patients). If they stated that they had improved and were on no further treatment, they were considered a treatment success. If not, patients were asked whether they had presented within the 2-week time period from discharge to follow-up telephone call to their local ED or general practitioner (primary care physician). Patients were asked whether they had received a further course of oral antibiotics or whether they were referred to their ED for admission and intravenous antibiotic treatment. When a patient stated that they were admitted to hospital for intravenous antibiotic treatment, they were considered to have undergone oral to intravenous antibiotic switch (primary outcome). At the time of study enrolment, outpatient parenteral 


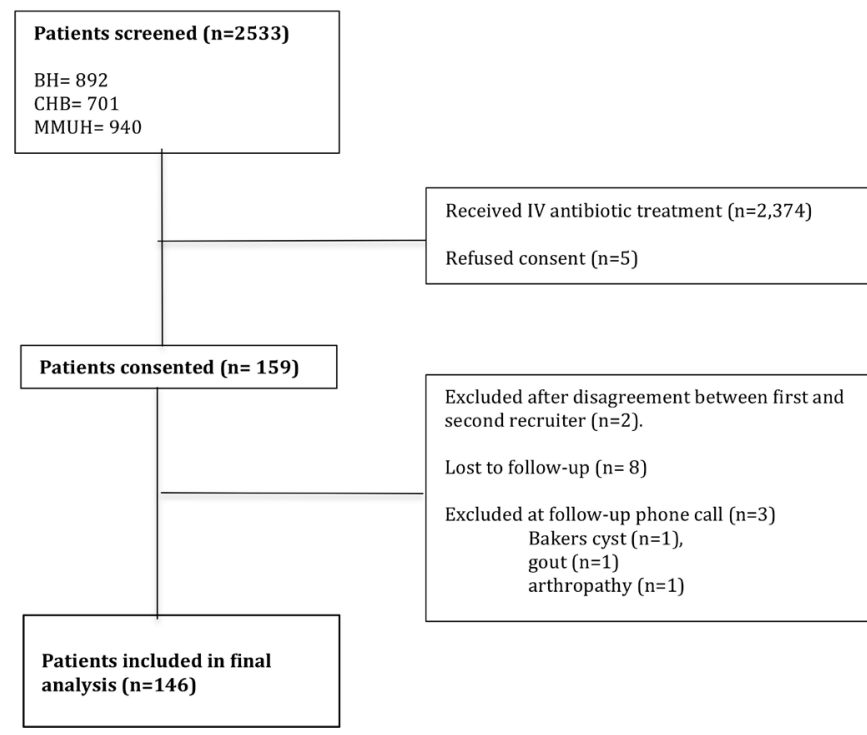

Figure 1 Flow diagram of patient screening and enrolment. BH, Beaumont Hospital; CHB, Connolly Hospital Blanchardstown; MMUH, Mater Misericordiae University Hospital.

antimicrobial therapy (OPAT) programmes in the study sites usually required hospital admission for 24 hours to allow for OPAT clinician assessment and initiation of treatment.

During telephone follow-up, patients were asked how they felt since their last visit with a description of any adverse events, whether they had to change their antibiotic due to side effects of treatment and whether they wished to receive final study results.

\section{Outcomes}

The primary outcome measure was the prevalence of oral to intravenous antibiotic treatment switch. Predictors of oral to intravenous switch were also determined. The secondary outcome measures were the prevalence of extending the course of oral antibiotic treatment by another clinician and the identification of the predictors associated with an extension of the course of oral antibiotic treatment. Assessment of interobserver reliability for relevant predictor variables and assessment of the eligibility and loss-to-follow-up rate were also measured. ${ }^{17}$

\section{Analysis}

The number of patients who had oral to intravenous antibiotic treatment switch is expressed as a percentage of the total number of patients prescribed oral antibiotic treatment at study enrolment. Univariate associations between explanatory variables and escalation or prolongation of treatment is expressed as OR with $95 \%$ CI. We planned to include the explanatory variables considered of prior clinical importance or having a threshold $p$ value of $\leq 0.15$ in the univariate analysis in a multivariable logistic regression (MVLR) model.

We planned for $10 \%$ of patient assessments to be completed by a second study recruiter. ${ }^{17}$ Interobserver agreement for each variable is assessed using the kappa coefficient and $95 \%$ CIs. A kappa coefficient $\geq 0.6$ is considered acceptable. For continuous variables, Lin's concordance coefficient is calculated.

Sample size is estimated based on determining the proportion of patients with oral to intravenous antibiotic switch. Using a 95\% CI for the proportion of patients with oral to intravenous antibiotic switch, a margin of error of 0.05 and an expected proportion of $10 \%$ based on an educated guess, and two recent studies suggesting that between $6.8 \%$ and $20.1 \%$ of ED patients with cellulitis had oral antibiotic treatment failure, the required sample was estimated to be a minimum of 152 patients. ${ }^{14} 15$ Data analysis was performed using Stata V.13.

\section{Patient and public involvement}

Patients were not involved with the design of this study but were asked whether they wished to receive the study results during telephone follow-up.

\section{RESULTS}

\section{Characteristics of study subjects}

Between March 2015 and September 2016, 159 patients with ABSSSIs were enrolled in this study, of which eight were lost to follow-up and five were excluded (figure 1). There were 67 patients with cellulitis arising de novo (45.9\%), 52 patients with infected wounds $(35.6 \%)$ and 27 patients with an abscess (18.5\%) resulting in 31 cases of 'purulent' cellulitis (21.2\%) and 115 cases of 'nonpurulent' cellulitis (78.8\%). Four patients $(2.7 \%)$ cultured MRSA, three of which were community-associated. Two of these cases occurred in visitors from CA-MRSA endemic areas. MRSA clonal typing was not performed.

Primary outcome: change in route of antibiotic administration from oral to intravenous antibiotic

Of the 146 patients analysed, 13 had a change in the route of antibiotic administration from oral to intravenous $(8.9 \%$; $95 \%$ CI $4.8 \%$ to $14.7 \%)$. On univariate analysis, increased white cell count (WCC), lesion surface area, athlete's foot and fungal toenail infection were associated with oral to intravenous antibiotic switch (table 1). MLVR was not conducted due to the small number of patients who underwent oral to intravenous antibiotic switch. No patient received OPAT in this study indicating that all episodes of oral to intravenous antibiotic switch were admitted to hospital.

\section{Chronic comorbidity}

chronic kidney disease, chronic liver disease and chronic cardiac disease.

\section{Chronic venous disease}

One of leg ulcer and/or venous eczema and/or phlebitis.

Diabetes mellitus

Type 1 or type 2 diabetes.

NPSS

Numerical pain scale score. 
Table 1 Predictor variables associated with oral to intravenous antibiotic switch

\begin{tabular}{|c|c|c|c|c|}
\hline Variable & $\begin{array}{l}\text { Total number } \\
(\%)^{*}\end{array}$ & $\begin{array}{l}\text { Number of } \\
\text { patients with } \\
\text { treatment } \\
\text { success (\%) }\end{array}$ & $\begin{array}{l}\text { Number of } \\
\text { patients with } \\
\text { treatment } \\
\text { switch }(\%)\end{array}$ & OR $(95 \% \mathrm{Cl})$ \\
\hline Patients & $146(100)$ & $133(91.1)$ & $13(8.9)$ & \\
\hline \multicolumn{5}{|l|}{ Age (years) } \\
\hline$<30$ & 29 (19.9) & 27 (20.3) & $2(15.4)$ & 1.00 \\
\hline $30-39$ & $32(21.9)$ & 31 (23.3) & $1(7.7)$ & 0.44 (0.04 to 5.07$)$ \\
\hline $40-49$ & $24(16.4)$ & $21(15.8)$ & $3(23.1)$ & $1.93(0.29$ to 12.61$)$ \\
\hline $50-59$ & $15(10.3)$ & $13(9.8)$ & $2(15.4)$ & $2.08(0.26$ to 16.44$)$ \\
\hline $60-69$ & $21(14.4)$ & $18(13.5)$ & $3(23.1)$ & 2.25 (0.34 to 14.83$)$ \\
\hline $70-79$ & $14(9.6)$ & $12(9.0)$ & $2(15.4)$ & $2.25(0.28$ to 17.91$)$ \\
\hline$\geq 80$ & $11(7.5)$ & $11(8.3)$ & 0 & \\
\hline Male gender & $95(65.1)$ & $86(64.7)$ & $9(69.2)$ & $0.81(0.24$ to 2.78$)$ \\
\hline Self-referral & 70 (47.9) & $64(48.1)$ & $6(46.1)$ & 0.87 (0.28 to 2.73$)$ \\
\hline Pre-ED antibiotic treatment & $35(24.0)$ & $32(24.1)$ & $3(23.1)$ & 0.89 (0.23 to 3.44$)$ \\
\hline \multicolumn{5}{|l|}{ Body mass index } \\
\hline$<25$ & $57(39.0)$ & $53(39.8)$ & $4(30.8)$ & 1.00 \\
\hline$\geq 25$ & $65(44.5)$ & $60(45.1)$ & $5(38.5)$ & $1.10(0.28$ to 4.33$)$ \\
\hline Missing & $24(16.4)$ & $20(15.0)$ & $4(30.8)$ & \\
\hline Active smoker & $45(30.8)$ & $41(30.8)$ & $4(30.8)$ & $1.00(0.28$ to 3.52$)$ \\
\hline Chronic comorbidity & $28(19.2)$ & $23(17.3)$ & $5(38.5)$ & $2.99(0.90$ to 9.97$)$ \\
\hline Peripheral vascular disease & $4(2.7)$ & $3(2.3)$ & $1(7.7)$ & 3.53 (0.34 to 36.60$)$ \\
\hline Chronic venous disease & $21(14.4)$ & $17(12.8)$ & $4(30.8)$ & 2.95 (0.82 to 10.66$)$ \\
\hline Diabetes mellitus & $8(5.5)$ & $7(5.3)$ & $1(7.7)$ & 1.64 (0.18 to 14.53$)$ \\
\hline Active intravenous drug use & $6(4.1)$ & $4(3.0)$ & $2(15.4)$ & $5.82(0.96$ to 35.40$)$ \\
\hline History of cellulitis in past year & $18(12.3)$ & $7(5.3)$ & $1(7.7)$ & 0.55 (0.68 to 4.54$)$ \\
\hline Previous surgery to affected body part & $22(15.1)$ & $20(15.0)$ & $2(15.4)$ & $1.00(0.20$ to 4.90$)$ \\
\hline Rigour/self-reported fever & $32(21.9)$ & $28(21.1)$ & $4(30.8)$ & $1.63(0.47$ to 5.70$)$ \\
\hline Objectively self-diagnosed fever prior to attendance & $34(23.3)$ & $30(22.6)$ & $4(30.8)$ & $1.51(0.43$ to 5.26$)$ \\
\hline Fever at triage & $17(11.6)$ & $17(12.8)$ & 0 & \\
\hline Average (SD) heart rate at triage $(\mathrm{bpm})$ & $81.0(13.0)$ & $80.6(13.3)$ & $84.8(9.3)$ & 1.05 (0.98 to 1.07$)$ \\
\hline Average (SD) systolic blood pressure at triage $(\mathrm{mm} / \mathrm{Hg})$ & $131.5(20.1)$ & $130.4(20.2)$ & $140.3(17.0)$ & $1.03(0.99$ to 1.06$)$ \\
\hline Average (SD) capillary blood glucose (mmol/L) & $6.4(3.3)$ & $5.7(1.4)$ & $11.3(6.1)$ & 1.67 (0.97 to 2.89$)$ \\
\hline \multicolumn{5}{|l|}{$\mathrm{C}$ reactive protein } \\
\hline$<10$ & $12(8.2)$ & $11(8.3)$ & $1(7.7)$ & 1.00 \\
\hline $10-<20$ & $8(5.5)$ & $7(5.3)$ & $1(7.7)$ & 1.57 (0.08 to 29.4$)$ \\
\hline$>20$ & $28(19.2)$ & $24(18.1)$ & $4(30.8)$ & $1.83(0.18$ to 18.4$)$ \\
\hline Missing values & $98(67.1)$ & $91(68.4)$ & $7(53.9)$ & \\
\hline Median (IQR) white cell count $\left(x \times 10^{9}\right) \dagger$ & $9.5(7.2-12)$ & $9.0(4.9)$ & $12(7.3)$ & $1.32(1.05$ to 1.67$)$ \\
\hline Average (SD) lesion surface area $\left(\mathrm{cm}^{2}\right) \dagger$ & $124.8(194.4)$ & $110.9(165.1)$ & $286.6(390.4)$ & 1.74 (1.09 to 2.79$)$ \\
\hline Purulent discharge & $31(21.2)$ & $28(21.1)$ & $3(23.1)$ & $1.13(0.29$ to 4.37$)$ \\
\hline Fluctuance from abscess & $27(18.5)$ & $23(17.3)$ & $4(30.8)$ & $2.13(0.60$ to 7.50$)$ \\
\hline Wound & $52(35.6)$ & $50(37.6)$ & $2(15.4)$ & $0.30(0.06$ to 1.40$)$ \\
\hline Ulcer & $15(10.3)$ & $13(9.8)$ & $2(15.4)$ & $1.66(0.33$ to 8.34$)$ \\
\hline Athlete's foott & $18(12.3)$ & $12(9.0)$ & $6(46.2)$ & 8.00 (2.31 to 27.71$)$ \\
\hline Fungal nail infection† & $15(10.3)$ & $10(7.5)$ & $5(38.5)$ & 7.25 (1.99 to 26.35$)$ \\
\hline Lymphangitis & $13(8.9)$ & $11(8.3)$ & $2(15.4)$ & $2.02(0.40$ to 10.27$)$ \\
\hline
\end{tabular}




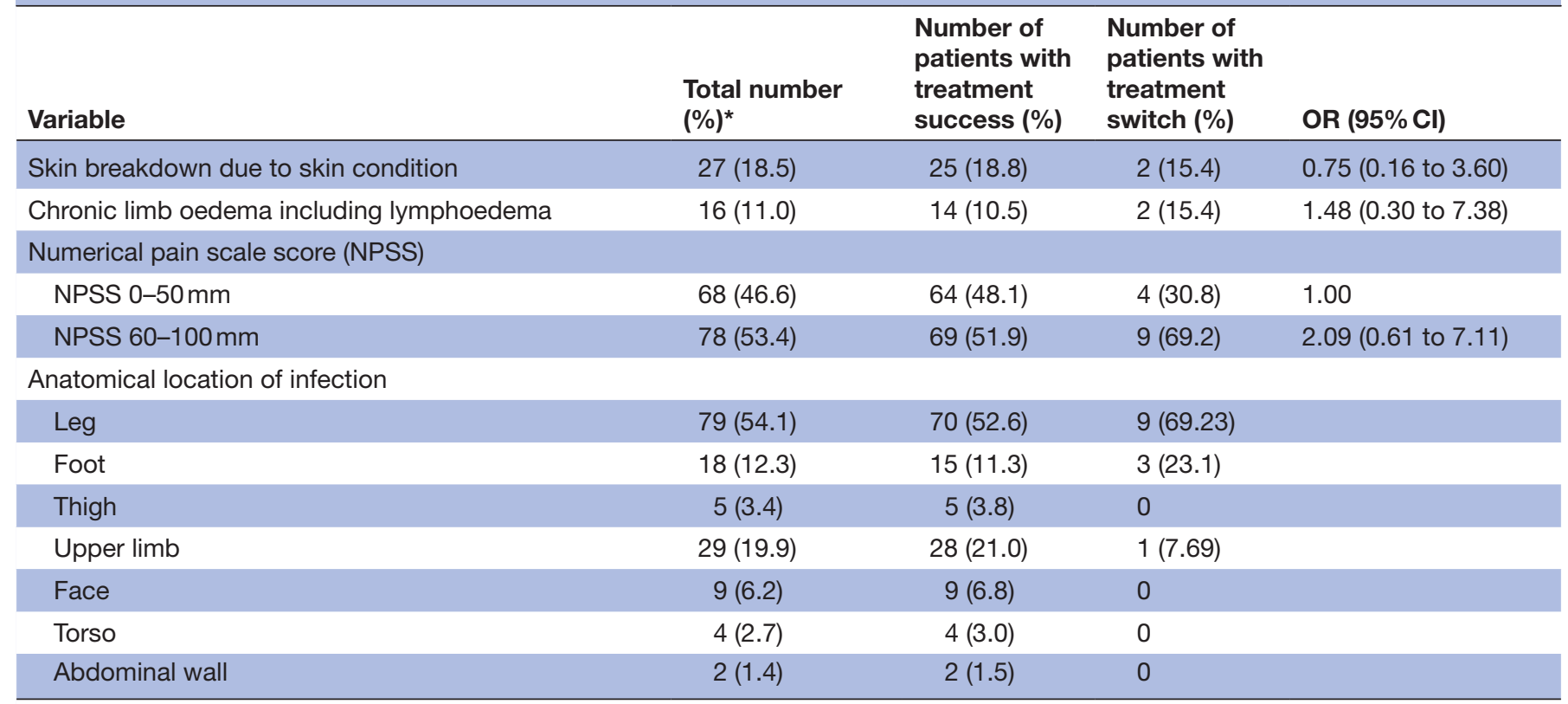

Significant variables are highlighted in bold.

*Significant variables analysed by univariate logistic regression (bold). †Unless otherwise stated.

ED, emergency department; NPSS, Numerical Pain Scale Score.

\section{Secondary outcome measure: extension of oral antibiotic treatment}

We excluded the 13 patients who had a change in route of antibiotic administration from oral to intravenous antibiotic (the primary outcome), performing analysis on 133 patients. Of these 133 patients, 33 received a further course of oral antibiotic $(24.8 \%$ (95\% CI $18.1 \%$ to $33.0 \%$ ). On univariate analysis lesion length, chronic limb oedema and purulent discharge were associated with extending the treatment course of oral antibiotic (table 2). MVLR was not performed due to the small number of patients with this outcome.

\section{Interobserver reliability}

Of the 146 patients recruited, an independent ED clinician performed a second assessment in $80(55 \%)$ patients (table 3). All variables had $\kappa \geq 0.6$ except for fluctuance $(\kappa=0.57 ; 95 \%$ CI 0.32 to 0.82$)$, lymphangitis $(\kappa=0.44$; $95 \%$ CI 0.12 to 0.77 ), presence of a wound $(\kappa=0.48$; $95 \%$ CI 0.27 to 0.69$)$ and chronic venous disease $(\kappa=0.57$;

Table 2 Predictor variables associated with extension of oral antibiotic treatment

\begin{tabular}{ll}
\hline $\begin{array}{l}\text { Predictors for oral antibiotic } \\
\text { treatment extension }\end{array}$ & OR $(\mathbf{9 5 \%} \mathbf{C l})$ \\
\hline Lesion length & $1.06(1.01$ to 1.11$)$ \\
\hline $\begin{array}{l}\text { Purulent discharge } \\
\begin{array}{l}\text { Chronic limb oedema including } \\
\text { lymphoedema }\end{array}\end{array}$ & $3.68(1.51$ to 8.95$)$ \\
\hline
\end{tabular}

95\% CI 0.32 to 0.82 ). No patients wished to receive study results.

\section{DISCUSSION}

To the best of our knowledge, this is the first prospective study to determine the prevalence and predictors of oral to intravenous treatment switch among ED patients with ABSSSIs in a European ED setting where CA-MRSA is not endemic. We found that $8.9 \%$ of ED patients with ABSSSIs had oral to intravenous antibiotic switch.

Existing knowledge on oral to intravenous antibiotic switch in ED patients with ABSSIs is limited to studies investigating treatment failure in cellulitis. Three previous Canadian studies of treatment failure for cellulitis investigated the predictors of treatment failure among patients who were prescribed both oral and intravenous antibiotics at enrolment. As a result, patients were likely to have varying severity of infection making comparison with this study difficult. ${ }^{14-16}$ Additionally, the definition of treatment failure differs between the three Canadian studies. ${ }^{14-16}$ In the first study, where treatment failure was defined as 'specialist consultation, hospital admission, requirement for IV antibiotics, or a surgical procedure', the trate was $6.8 \%$ among 29 patients initially treated with oral antibiotic therapy. ${ }^{14}$ In the second study, the treatment failure rate was $21.1 \%$ among 185 patients initially treated with oral antibiotics. ${ }^{15}$ In this study, treatment failure was defined as change in antibiotic therapy from one oral antibiotic to another, from oral to intravenous antibiotic, or hospital admission, a combination of both 
Table 3 Assessment of interobserver reliability for predictor variables

\begin{tabular}{|c|c|c|c|}
\hline Variable & $\mathbf{N}$ & $\begin{array}{l}\text { Agreement - } \kappa \text { coefficient } \\
\text { (unless otherwise stated) }\end{array}$ & $\begin{array}{l}\kappa \text { coefficient }>0.6 \text { (as } \\
\text { specified in protocol) }\end{array}$ \\
\hline Location of infection* & 73 & $0.95(95 \% \mathrm{Cl} 0.87$ to 1.00$)$ & Yes \\
\hline Lesion width (cm) & 74 & $0.91(95 \% \mathrm{Cl} 0.88$ to 0.95$) \dagger$ & Yes \\
\hline Lesion surface area $\left(\mathrm{cm}^{2}\right)$ & 68 & $0.98(95 \%$ Cl 0.97 to 0.99$) \dagger$ & Yes \\
\hline Lymphangitis & 77 & $0.44(95 \% \mathrm{Cl} 0.12$ to 0.77$)$ & No \\
\hline Ulcer & 78 & $0.62(95 \% \mathrm{Cl} 0.36$ to 0.88$)$ & Yes \\
\hline Wound & 76 & $0.48(95 \% \mathrm{Cl} 0.27$ to 0.69$)$ & No \\
\hline Athlete's foot & 75 & 0.77 (95\% Cl 0.69 to 0.96$)$ & Yes \\
\hline Chronic comorbidity & 76 & 0.83 (95\% Cl 0.68 to 0.99$)$ & Yes \\
\hline Peripheral vascular disease & 73 & $0.79(95 \% \mathrm{Cl} 0.40$ to 1.00$)$ & Yes \\
\hline Venous disease & 74 & 0.57 (95\% Cl 0.32 to 0.82$)$ & No \\
\hline Diabetes mellitus & 76 & $0.79(95 \% \mathrm{Cl} 0.50$ to 1.00$)$ & Yes \\
\hline Current intravenous drug use & 76 & $0.74(95 \% \mathrm{Cl} 0.39$ to 1.00$)$ & Yes \\
\hline
\end{tabular}

*Bootstrap estimation used to calculate the $\mathrm{Cl}$.

†Lin's concordance coefficient.

our primary and secondary outcomes. In the third study, a retrospective review of 500 patients receiving oral antibiotics in an ED, ${ }^{16}$ treatment failure was defined as hospital admission, change in type of oral antibiotic or change from oral to intravenous antibiotic. ${ }^{16}$ In this study, where the overall rate of treatment failure was $29.5 \%, 20 \%$ of patients received an intravenous antibiotic dose in the ED before being discharged home with an oral antibiotic prescription. ${ }^{16}$

Although we identified some predictors on univariate analysis that were associated with oral to intravenous antibiotic switch, they may be of limited clinical utility given the relatively small number of patients. Increased size of erythema is an intuitive measure of clinical severity, although it has not been associated with treatment failure in previous studies. ${ }^{14-16}$ One previous prospective study that measured infection diameter among eligible patients showed that it was not significant. ${ }^{15}$ Measurement of WCC was only performed in $35 \%$ of the patient cohort as part of their routine care, which reflects standard clinical practice but limits further the usefulness of this predictor variable. In those patients in whom WCC was measured, there was a small association with oral to intravenous switch. Athlete's foot and fungal nail infection are risk factors for developing cellulitis. ${ }^{18}$ Only one other prospective study of treatment failure in cellulitis examined eligible patients for toe web intertrigo but found no association. ${ }^{15}$ Although the association between fungal nail infection/athlete's foot and treatment escalation in cellulitis is unclear, since it is associated with development of skin infections, it is intuitively logical that it should be concurrently treated.

In order to allow comparison with similar studies, we asked patients whether they had received further courses of oral antibiotic treatment between the time of discharge from the ED and the follow-up telephone call. Almost $25 \%$ of patients $(24.8 \%$; $95 \%$ CI $18.1 \%$ to $33.0 \%$ ) reported that they received a further course of oral antibiotic treatment. Since this outcome measure was based on patient recall and without any objective measure of severity by a healthcare provider, it should be interpreted with caution. Although the analysis is speculative, we found that increased lesion length, purulent discharge and lymphoedema/chronic leg oedema were associated with oral antibiotic treatment exceeding 7 days. These results are hypothesis generating for future studies. Since the recommended treatment duration for patients with lymphoedema is at least 14 days, it is unsurprising that it is associated with longer courses of oral antibiotic treatment. ${ }^{19}$ Lymphoedema was also associated with treatment failure in the only other prospective cohort study of cellulitis treatment failure along with fever at triage, leg ulcers, prior cellulitis and cellulitis at a wound site. ${ }^{15}$ Clinicians should, therefore, be mindful of the potential need for prolonged antibiotic treatment in this group of patients. 
Consistent with the existing literature, there was poor interobserver agreement on the presence of subjective clinical features of cellulitis; in contrast, there was good interobserver agreement for objectively measured variables such as the diameter of the cellulitis lesion and the presence of purulent discharge. ${ }^{14}$ Although this likely reflects 'real-world' clinical practice and enhances the external validity of our findings, these results also highlight the inconsistent manner in which clinicians perceive subjective clinical features such as fluctuance and lymphangitis in patients with ABSSSI, and therefore the inherent difficulties in performing research in this area.

The methodology of this study may also help determine the feasibility of developing a clinical prediction rule that can permit a more evidence-based approach to empirically prescribing oral or intravenous antibiotics for ED patients with ABSSSIs. ${ }^{17}$ Based on our findings, a study measuring only 10 explanatory variables would require a minimum of approximately 1600 patients.

\section{Limitations}

This study has several limitations, many of them common to other studies of ABSSSI treatment. We were also unable to measure missed enrolments due to the inaccurate coding of patients with ABSSSI in the three study sites, and this raises the likelihood of selection bias. Each participating ED has a unique information system that led to difficulty measuring the proportion of discharged patients who received oral antibiotics and who were not enrolled in this study. Data from the Hospital In-Patient Enquiry (HIPE) database reveals that 2374 patients with cellulitis received intravenous antibiotic treatment during the study period in the three participating EDs and were not enrolled in this study. HIPE is the health information system designed to collect clinical and administrative data on discharges from, and deaths in, acute hospitals in Ireland. The HIPE system is intended to gather information on patient discharges after treatment in the inpatient setting and is not designed for data collection in the outpatient, ED or community settings. ${ }^{20}$ We are, therefore, unable to accurately determine the proportion of ED patients with ABSSSIs treated with oral antibiotics that we failed to enrol in this study.

Cellulitis diagnosis and risk stratification is a subjective clinical process. There is no diagnostic gold standard for cellulitis. Evidence from observational studies and audits of practice indicate that clinicians are often erroneous when making a diagnosis of cellulitis. One UK study that examined the transfer of care of cellulitis from general physicians to dermatologists in a general hospital found that $33 \%$ of the 635 patients referred with lower limb cellulitis had alternative diagnoses that did not require admission and $28 \%$ had an underlying skin condition that required dermatological treatment. ${ }^{21}$ A recent systematic review has shown that between $6 \%$ and $37 \%$ of patients enrolled in 20 randomised controlled trials (RCTs) of antibiotic treatment for cellulitis were placed in the 'treatment failure' category. ${ }^{22}$ This wide range of reported treatment failure data is thought to be due to the enrolment of patients with cellulitis mimics. It is also due to discrepancies with regards to how cellulitis is diagnosed even in the relatively rigid RCT setting. In order to mitigate against this, only clinicians with at least 2 years' clinical experience in emergency medicine were permitted to enrol patients in this study. Inter-rater agreement around the diagnosis of predictor variables and the presenting ABSSSI occurred in 55\% of enrolled cases, and departmental teaching on ABSSSI diagnosis and exclusion of cellulitis mimics among study recruiters was performed prior to study commencement at each enrolling site.

The decision to administer oral or intravenous treatment for an episode of ABSSSI may be based on a combination of factors such as patient concerns and preferences and physician practice. More often, it is based on physician gestalt rather than any objective parameters such as lesion size or the result of a laboratory investigation. At enrolment, inter-rater agreement for diagnosis and route of antibiotic administration occurred in $55 \%$ of patients. However, at follow-up, the decision to switch from oral to intravenous antibiotic treatment was made by a single clinician, not necessarily associated with this research study. This means that reverse causality may be associated with some of the identified clinical predictors such as cellulitis lesion size and WCC count. Also, as only $8.9 \%$ of patients required oral to intravenous antibiotic switch, this pilot study was not adequately powered to measure associations between explanatory variables and oral to intravenous antibiotic switch. In this context, further research is required before any of the identified predictor is used to guide clinical judgement.

The use of telephone follow-up introduces the possibility of recall bias and is subjectively based on the patient's perception of decreasing size of the cellulitis lesion and 'cure'. However, basing study outcomes on the patient's perception of their clinical condition makes the relevant outcome measures patient centred. During the telephone follow-up, we mitigated against recall bias by framing the questions to aid accurate recall. We also mitigated against recall bias by ensuring the time interval between the expected resolution of an episode of acute cellulitis that has responded to empiric oral antibiotic treatment and the telephone follow-up was as short as possible.

\section{CONCLUSION}

In this pilot study of adult ED patients with ABSSSI, 8.9\% of patients discharged on 7 days of oral flucloxacillin were switched to intravenous antibiotics. Almost $25 \%$ of patients received an extended course of oral antibiotic treatment for their ABSSSI. The identified predictors of oral to intravenous switch in this study require further investigation in a larger study.

Author affiliations

${ }^{1}$ Emergency Care Research Unit, Royal College of Surgeons Ireland, Dublin, Ireland 
${ }^{2}$ Department of Emergency Medicine, Beaumont Hospital, Dublin, Ireland

${ }^{3}$ Department of Emergency Medicine, Connolly Hospital Blanchardstown, Blanchardstown, Dublin, Ireland

${ }^{4}$ HRB Centre For Primary Care Research, Department of General Practice, Royal College of Surgeons Ireland, Dublin, Ireland

${ }^{5}$ Department of Emergency Medicine, Mater Misericordiae University Hospital, Dublin, Ireland

\section{Twitter Michael Quirke @quirkemi}

Contributors MQ, AW, and TF conceived and designed the study. MQ, AM, JM and AW obtained research and ethics committee approval from each study site and took overall responsibility for recruitment and data collection at each site. MQ, NM, JV and SK recruited and followed up study participants at each recruiting site. MQ and NM took responsibility for data collection and management. FB provided statistical advice on study design and analysed the data. $\mathrm{MQ}$ drafted the manuscript, and all authors contributed substantially to its revision. AW takes responsibility for the paper as a whole.

Funding The authors have not declared a specific grant for this research from any funding agency in the public, commercial or not-for-profit sectors.

Competing interests None declared.

Patient consent for publication Not required.

Ethics approval The study was approved by each hospital ethics committee.

Provenance and peer review Not commissioned; externally peer reviewed.

Data availability statement All data relevant to the study are included in the article. Data available on request from the corresponding author.

Open access This is an open access article distributed in accordance with the Creative Commons Attribution Non Commercial (CC BY-NC 4.0) license, which permits others to distribute, remix, adapt, build upon this work non-commercially, and license their derivative works on different terms, provided the original work is properly cited, appropriate credit is given, any changes made indicated, and the use is non-commercial. See: http://creativecommons.org/licenses/by-nc/4.0/.

ORCID iDs

Michael Quirke http://orcid.org/0000-0003-4179-2748

Fiona Boland http://orcid.org/0000-0003-3228-0046

Tom Fahey http://orcid.org/0000-0002-5896-5783

Abel Wakai http://orcid.org/0000-0003-2021-2388

\section{REFERENCES}

1 Eron LJ, Lipsky BA, Low DE, et al. Managing skin and soft tissue infections: expert panel recommendations on key decision points. $J$ Antimicrob Chemother 2003;52:3i-17.

2 Ansari F, Erntell M, Goossens $\mathrm{H}$, et al. The European surveillance of antimicrobial consumption (ESAC) point-prevalence survey of antibacterial use in 20 European hospitals in 2006. Clin Infect Dis 2009:49:1496-504.

3 Dong SL, Kelly KD, Oland RC, et al. Ed management of cellulitis: a review of five urban centers. Am J Emerg Med 2001;19:535-40.

4 Gunderson CG. Cellulitis: definition, etiology, and clinical features. Am J Med 2011;124:1113-22.
5 Pallin DJ, Binder WD, Allen MB, et al. Clinical trial: comparative effectiveness of cephalexin plus trimethoprim-sulfamethoxazole versus cephalexin alone for treatment of uncomplicated cellulitis: a randomized controlled trial. Clin Infect Dis 2013;56:1754-62.

6 US Food and Drug Administration, Center for Drug Evaluation and Research. Guidance for industry. acute bacterial skin and skin structure infections: developing drugs for treatment, 2013. Available: http://www.fda.gov/downloads/Drugs/Guidances/ ucm071185.pdf

7 Stevens DL, Bisno AL, Chambers HF, et al. Practice guidelines for the diagnosis and management of skin and soft tissue infections: 2014 update by the infectious diseases Society of America. Clin Infect Dis 2014;59:e10-52.

8 Pallin DJ, Egan DJ, Pelletier AJ, et al. Increased US emergency department visits for skin and soft tissue infections, and changes in antibiotic choices, during the emergence of community-associated methicillin-resistant Staphylococcus aureus. Ann Emerg Med 2008;51:291-8.

9 Edelsberg J, Taneja C, Zervos M, et al. Trends in US hospital admissions for skin and soft tissue infections. Emerg Infect Dis 2009;15:1516-8.

10 Bouchiat C, Curtis S, Spiliopoulou I, et al. Mrsa infections among patients in the emergency department: a European multicentre study. $J$ Antimicrob Chemother 2017;72:372-5.

11 Clinical Resource Efficiency Support Team. Crest guidelines on the management of cellulitis in adults. Northern Ireland: DHSS, 2005: 1-31.

12 Ki V, Rotstein C. Bacterial skin and soft tissue infections in adults: a review of their epidemiology, pathogenesis, diagnosis, treatment and site of care. Can J Infect Dis Med Microbiol 2008;19:173-84.

13 Marwick C, Rae N, Irvine N, et al. Prospective study of severity assessment and management of acute medical admissions with skin and soft tissue infection. J Antimicrob Chemother 2012;67:1016-9.

14 Murray H, Stiell I, Wells G. Treatment failure in emergency department patients with cellulitis. CJEM 2005;7:228-34.

15 Peterson D, McLeod S, Woolfrey K, et al. Predictors of failure of empiric outpatient antibiotic therapy in emergency department patients with uncomplicated cellulitis. Acad Emerg Med 2014:21:526-31.

16 Yadav K, Suh KN, Eagles D, et al. Predictors of oral antibiotic treatment failure for Nonpurulent skin and soft tissue infections in the emergency department. Acad Emerg Med 2019;26:51-9.

17 Quirke M, Boland F, Fahey T, et al. Prevalence and predictors of initial oral antibiotic treatment failure in adult emergency department patients with cellulitis: a pilot study. BMJ Open 2015;5:e008150.

18 Quirke M, Ayoub F, McCabe A, et al. Risk factors for nonpurulent leg cellulitis: a systematic review and meta-analysis. $\mathrm{Br} J$ Dermatol 2017;177:382-94.

19 Mortimer PS, Cefai C, Keeley V. Consensus document on the management of cellulitis in lymphoedema. British Lymphology Society and Lymphoedema Support Network 2005.

20 Wiley MM. Using HIPE data as a research and planning tool: limitations and opportunities: a response. Ir J Med Sci 2005; $174: 52-7$

21 Levell NJ, Wingfield CG, Garioch JJ. Severe lower limb cellulitis is best diagnosed by dermatologists and managed with shared care between primary and secondary care. $\mathrm{Br} J$ Dermatol 2011;164:1326-8.

22 Obaitan I, Dwyer R, Lipworth AD, et al. Failure of antibiotics in cellulitis trials: a systematic review and meta-analysis. Am J Emerg Med 2016;34:1645-52. 